\title{
Prevalencia de Escherichia coli resistente a colistina y cefalosporinas de tercera generación aisladas de carcasas y ciegos de pollos Broiler en Quito-Ecuador
}

\author{
Márquez, Andrea $^{1}$; Ortega-Paredes, David ${ }^{1 *}$; Fernández-Moreira, Esteban ${ }^{2}$; Vinueza Burgos, Christian $^{1}$ \\ ${ }^{1}$ Unidad de Investigación de Enfermedades Transmitidas por Alimentos y Resistencia a los \\ Antimicrobianos (UNIETAR), Quito, Ecuador. \\ 2 Universidad de las Américas. Facultad de Medicina, Quito, Ecuador.
}

e-mail: daortegap@uce.edu.ec

Palabras clave: Broiler, cefalosporinas de tercera generación, colistina, Escherichia coli, mcr.

INTRODUCCIÓN: La colistina se considera como última alternativa en el tratamiento de las infecciones causadas por enterobacterias resistentes a los carbapenémicos. La resistencia móvil a este antimicrobiano se encuentra mediada por los genes $\mathrm{mcr}$ (mobile colistin resistence), de los cuales se han reportado 9 tipos. Estos genes codifican fosfoetanolamina transferasas capaces de modificar el lipopolisacárido de la membrana externa de la bacteria para disminuir su afinidad por la colistina. Los genes $\mathrm{mcr}$ han sido relacionados con la producción cárnica, debido a los grandes volúmenes de antibióticos que se emplean en las explotaciones animales.

OBJETIV0: Determinar la prevalencia de los genes $\operatorname{mcr}$ ( 1 a 5 ) en aislados de Escherichia coli resistente a cefalosporinas de tercera generación (R-C3G) en granjas avícolas y carcasas de pollo en el área de influencia del Distrito Metropolitano de Quito (DMQ).

MATERIALES Y MÉTODOS: Se analizaron 385 aislados de E. coli R-C3G (2018), divididos en 263 aislados de carcasas de pollo comercializadas en Quito y 122 de granjas avícolas que abastecen la ciudad. El perfil de susceptibilidad se obtuvo mediante el sistema Vitek ${ }^{\circledR} 2$ y las MIC de colistina por microdilución. Los genes $m c r-1,2,3$, 4 y 5 se analizaron mediante PCR según lo descrito por Rebelo y colaboradores. [1]
RESULTADOS: El gen $m c r-1$ fue el único identificado, con una prevalencia de 11,9\% (46/385). Al analizar estos datos por componente se encontró un 10,9\% (26/263) en carcasas y $16,4 \%(20 / 122)$ en granjas $(p=0,06)$. Los aislados $m c r-1$ positivos presentaron MIC para colistina entre 2 y $8 \mu \mathrm{g} / \mathrm{ml}$. Exhibiendo, además patrones de multirresistencia (resistentes a $\geq 3$ familias de antimicrobianos).

CONCLUSIONES: El incremento en la prevalencia de mcr-1 en granjas avícolas, de $3,4 \%$ en pool de ciegos en 2014-2015 [2] a 16,4\% en 2018, p<0,05, indica el establecimiento de este determinante en la producción avícola y su posible incremento por presión selectiva y transferencia horizontal de genes en estos ambientes. Su localización en carcasas de pollo, sugieren su diseminación hacia los consumidores.

\section{REFERENCIAS:}

[1] Rebelo AR, Bortolaia V, Kjeldgaard JS, Pedersen SK, Leekitcharoenphon P, Hansen IM, Guerra B, Malorny B, Borowiak M, Hammerl JA, Battisti A, Franco A, Alba P, Perrin-Guyomard A, Granier SA, De Frutos Escobar C, Malhotra-Kumar S, Villa L, Carattoli A, Hendriksen RS. Multiplex PCR for detection of plasmid-mediated colistin resistance determinants, mcr-1, mcr-2, mcr-3, mcr- 4 and mcr-5 for surveillance purposes, Euro Surveill. 2018; 23(6).

[2] Vinueza-Burgos C, Ortega-Paredes D, Narváez 
C, De Zutter L, Zurita J. Characterization of cefotaxime resistant Escherichia coli isolated from broiler farms in Ecuador. PlosOne. [Internet]. 2019. Disponible en: doi.org/10.1371/journal. pone.0207567. 